\title{
Practice-based learning: Integrating SGBV screening into health facilities in refugee contexts
}

\author{
Chi-Chi Undie \\ Population Council \\ Josephine Ngebeh \\ Joanina Karugaba \\ Harriet Birungi \\ Population Council \\ Michael Mbizvo \\ Population Council
}

Follow this and additional works at: https://knowledgecommons.popcouncil.org/departments_sbsr-rh

Part of the Demography, Population, and Ecology Commons, Family, Life Course, and Society Commons, International Public Health Commons, Medicine and Health Commons, and the Migration Studies Commons How does access to this work benefit you? Let us know!

\section{Recommended Citation}

Undie, Chi-Chi, Josephine Ngebeh, Joanina Karugaba, Harriet Birungi, and Michael Mbizvo. 2019.

"Practice-based learning: Integrating SGBV screening into health facilities in refugee contexts," Sauti/ VOICE Program Brief no. 4. Nairobi: UNHCR EHAGL Africa Bureau and Population Council. 


\section{Practice-Based Learning: Integrating SGBV Screening into Health Facilities in Refugee Contexts}

\section{Introduction}

Sexual and gender-based violence (SGBV) 'screening' refers to the standardized assessment of clients for SGBV incidents, regardless of reasons for presenting at a health facility. This practice has been shown to be feasible and effective in various countries and contexts in the East and Southern African region, resulting in proactive identification of female survivors, and their successful referrals for comprehensive SGBV care. In the last decade, health facilities in the region are increasingly eager to incorporate such screening within the normal protocols of their health care providers.

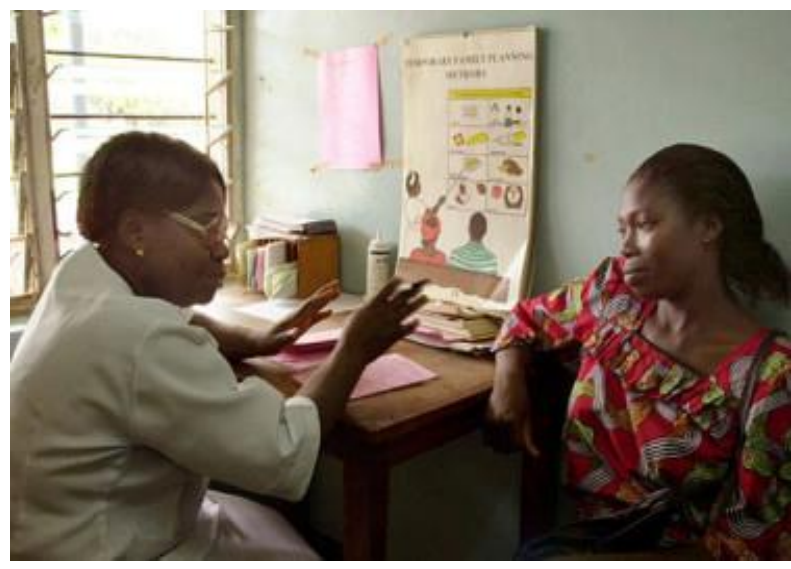

In collaboration with the Population Council-led Africa Regional SGBV Network, the UNHCR East, Horn of Africa, and Great Lakes (EHAGL) Africa Bureau has worked to integrate SGBV screening protocols within its country operations since 2017. This brief report outlines practical lessons from training and implementation efforts in refugee settings.

\section{Intervention Description}

The SGBV screening intervention trains health providers to appropriately utilize a four-question screening tool with female clients to determine their current and lifetime SGBV experiences, and to appropriately refer identified survivors for on-site SGBV care. The tool is intended to be used with every female client in a certain age range (to be determined by intervention implementers, with guidance from the trainer), to ask them about their SGBV experiences, every time a female client presents before the provider-unless she has already been identified as a SGBV survivor through this process.

Health facilities are only eligible to participate in this intervention if they have an SGBV Response Unit on site (to facilitate the referral process), and trained providers are only eligible to begin screening if their work stations provide audio-visual privacy. The provider training session lasts for one day, and an online training manual of the East, Central and Southern Africa Health Community is available to support the session: www.popcouncil.org/uploads/pdfs/2016RH_IPV-manual.pdf. 


\section{Participating Countries}

The UNHCR EHAGL Africa Bureau includes 12 countries in the East, Horn, and Great Lakes regions of Africa. Seven of these countries chose to receive technical support from the Africa Regional SGBV Network, and by December 2019, four countries (Rwanda, South Sudan, Uganda, Zambia) had received training to facilitate implementation of SGBV screening in a total of 12 refugee camps and settlements.

\section{Lessons}

Lessons from actual SGBV screening processes have been documented for consideration by UNHCR programs, as well as practitioners interested in introducing SGBV screening protocols in refugee settings in particular.

\section{Notions of Privacy}

Notions of privacy may differ in health facilities situated in refugee settings compared to those that are not. Resource constraints that characterize refugee contexts often create space limitations in health facilities, which may result in consultation rooms being used by several providers attending to several clients simultaneously. It is critical for trainers to personally visit the work station of every trained provider prior to, or following, an SGBV screening training session. Providers are often so accustomed to their work space that they honestly believe it offers audio-visual privacy until they see it through the perspective of an external party.

Providers operating from work spaces that do not offer complete audio-visual privacy are not eligible to screen clients for SGBV until the situation is rectified. Situations have resulted in all providers originally selected for SGBV screening training actually turning out to be ineligible to screen patients due to the fact their consultation rooms were not private enough. In those specific cases, screening responsibilities were eventually restricted solely to HIV service providers, who were the only providers with adequate work station privacy.

\section{Starting Age of SGBV Screening}

At what age should SGBV screening start? This is a question providers will discuss and address during their training session. It should be noted, due to contextual differences, that ages are bound to differ between refugee camps in the same country. In some refugee camps, health providers point out that forced intimate partnerships are experienced so early in life by females that they must screen females as young as 13 (note that the screening tool mainly contains questions on intimate partner violence). Whatever starting age is selected, the general rule is that females should only be screened for SGBV when they present at a health facility unaccompanied, which helps ensure that screening is completely private (even for younger females), and that ethical standards are maintained.

\section{Interpreting Considerations}

Having local providers use vernacular language and vocabulary to communicate with their clients is not unusual when the host community constitutes the majority of the client population. In refugee settings, however, sometimes providers and most clients do not speak the same language, and in such cases, interpreters are used-even for highly confidential services such as HIV care. In such cases (i.e. where having an interpreter involved in client consultations is the health facility's norm), a decision may be made to involve interpreters in SGBV screening as well. Interpreters in that case would need to participate in the SGBV screening training session along with health providers, to ensure the screening questions are conveyed appropriately and accurately. 


\section{Resolving Human Resource Capacity Issues}

With SGBV screening comes an increase in survivors seeking comprehensive care at SGBV Response Units. Many health facilities are concerned about under-reporting by survivors and are eager to experience this increase in numbers. The reality is, however, that once the increase begins, SGBV Response Units are often unprepared and overburdened due to staffing limitations. To resolve this predicament, some health facilities have embraced a staggered approach, screening only in certain departments on specific days of the week. This process is facilitated by a screening schedule for participating departments in the health facility concerned, and can be a useful way of introducing screening in a controlled manner until staffing can be increased at SGBV Response Centers.

\section{Documentation}

Documenting simple screening statistics can help a health facility (and UNHCR at large) monitor the progress of the SGBV screening intervention. Screening statistics such as the following could be collated: How many women were screened in the last month? Of these, how many were identified as experiencing SGBV? Of these, how many were referred to the SGBV Response Unit? Of these, how many received care at the SGBV Response Unit?

A patient filing system can help to ease the documentation process (e.g. a screening tool can be stapled into each client's file to track whether she is experiencing violence or has been referred). In many refugee settings in the region, however, patient filing systems do not exist at health facilities. Nonetheless,

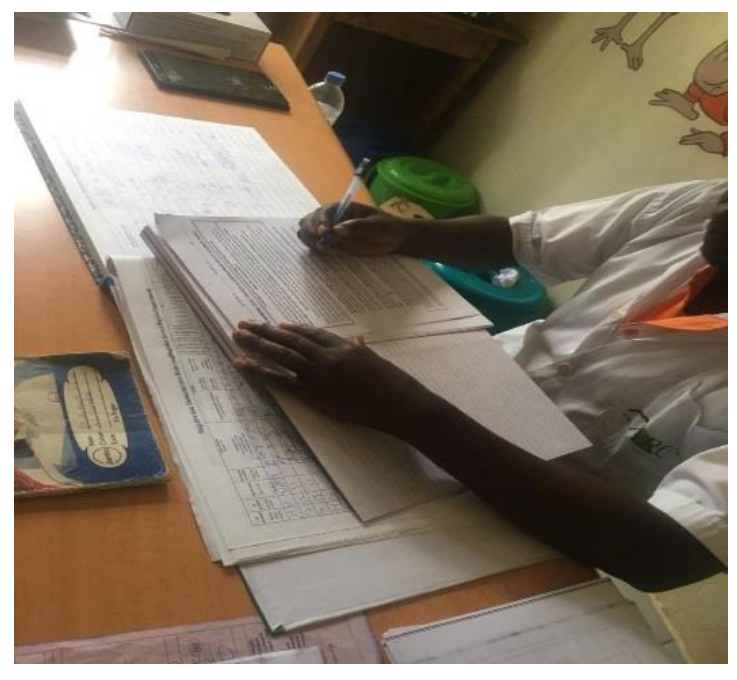
documentation can still occur by having trained providers store each completed screening tool in a box file, and by having the health facility's SGBV Focal Person collect all completed screening tools from each participating clinic every month.

The information from these tools would then be collated, in addition to simple service statistics from the SGBV Response Unit, showing how many female clients were referred there (and received SGBV services) as a result of being screened. Of all participating refugee camps and settlements, only Zambian health facilities are currently using smart cards to facilitate documentation (e.g. patient history). Such technology can be helpful in ensuring survivors are not repeatedly screened after already having been identified and referred. 


\section{References}

Laisser RM, Nyström L, Lindmark G, Lugina HI, Emmelin M. 2011. Screening of women for intimate partner violence: A pilot intervention at an outpatient department in Tanzania. Global Health Action 4(1).

Undie C., Maternowska M. C., Mak'anyengo M., Birungi H., Keesbury J., Askew I. 2012. Routine screening for intimate partner violence in public health care settings in Kenya: An assessment of acceptability. APHIA II OR Project in Kenya/ Population Council: Nairobi, Kenya.

Undie C., Maternowska M. C., Mak'anyengo M., Askew I. 2013. Feasibility of Routine Screening for Intimate Partner Violence in Public Health Care Settings in Kenya. Nairobi: Population Council.

Undie C., Maternowska M. C., Mak'anyengo M., Askew I. 2016. Is routine screening for intimate partner violence feasible in public health care settings in Kenya? Journal of Interpersonal Violence 31(2): 282-301.

Undie C., Birungi H., Namwebya J., Taye W., Maate L., Mak'anyengo M., Katahoire A., Kazungu D.A., Kusasira D, Mirghani Z., Karugaba J. 2016. Screening for Sexual and Gender-Based Violence in Emergency Settings in Uganda: An Assessment of Feasibility. Nairobi, Kenya: Population Council.

Vu, A., Wirtz, A.L., Bundgaard, S., Nair, A., Luttah, G., Ngugi, S., Glass, N. 2017. Feasibility and acceptability of a universal screening and referral protocol for gender-based violence with women seeking care in health clinics in Dadaab refugee camps in Kenya. Global Mental Health 4(e21).

Wirtz, A.L., Glass, N., Pham, K. et al. 2016. Comprehensive development and testing of the ASIST-GBV, a screening tool for responding to gender-based violence among women in humanitarian settings. Conflict and Health 10(7).

Since 2006, the Population Council-led Africa Regional SGBV Network has worked to build effective responses to SGBV in low-resource settings, focusing on those who have experienced violence, as well as on violence prevention. From 2018-2020, the network is collaborating with the UNHCR EHAGL Africa Bureau in Nairobi, Kenya, to address the needs of survivors in refugee settings in the East, Horn, and Great Lakes Regions of Africa through the ViOlence Response and Prevention through Information, Communication, and Education (VOICE) project. 'Voice' is translated as 'Sauti' in Kiswahili, and represents the project's emphasis on amplifying the voices of SGBV survivors and the efforts of the network's civil society organizations that work with them, in order to broaden the reach of effective SGBV responses across the region.

(C)2019 UNHCR EHAGL Africa Bureau and the Population Council, Inc.

Citation: Chi-Chi Undie, Josephine Ngebeh, Joanina Karugaba, Harriet Birungi, Mike Mbizvo. 2019. 'The Global Compact on Refugees: How the Sauti/VOICE Project Fits.' The Sauti/VOICE Program Brief Series, Brief 4. Nairobi, Kenya: UNHCR EHAGL Africa Bureau and Population Council.

UNHCR EHAGL Africa Bureau Contact: Josephine Ngebeh UNHCR EHAGL Africa Bureau APHRC Campus, Kitisuru P. 0. Box 43801-00100

Nairobi, Kenya ngebeh@unhcr.org
UNHCR Geneva Contact: Joanina Karugaba UNHCR Geneva Case Postale 2500 1211 Genève 2 Depôt Switzerland karugaba@unhcr.org

\author{
Africa Regional SGBV Network \\ Contact: \\ Chi-Chi Undie \\ Population Council \\ Avenue 5, Rose Avenue \\ Hurlingham \\ P. O. Box 17643-00500 \\ Nairobi, Kenya \\ cundie@popcouncil.org
}

